\title{
Letting Go of the War on Death: Time for Physicians to Embrace the Art of Dying
}

\author{
Gary Tzu* \\ Professor Emeritus, Health Sciences, Canada
}

*Corresponding author: Gary Tzu, PhD, LLB, Professor Emeritus, Health Sciences, University of Lethbridge President, Paradoxica Institute Ltd. (paradoxica.org) 606 Front Street, Nelson, BC V1L 6N8, Canada

\section{ARTICLE INFO}

Received: 幽 December 19, 2019

Published: 仹January 07, 2020

\section{ABSTRACT}

Citation: Gary Tzu. Letting Go of the War on Death: Time for Physicians to Embrace the Art of Dying. Biomed J Sci \& Tech Res 24(3)-2020. BJSTR. MS.ID.004043.

\section{Opinion}

There is a huge calamity that has been going on in the medical profession particularly with those doctors who are dealing with areas intimately related to possible pending death. There is no better example than working in the cancer field. The issue is that we live in a fear of death almost a death phobia culture, and the doctors are a prime example of that, as they fight against death like a big army battle in which they are destined to ultimately lose. Transpersonal-Integral philosopher Ken Wilber put death as part of the existential developmental level in his spectrum of development model which is level six out of ten developmental levels Tzu [1]. The levels beyond six are stages of progressive development beyond ego preoccupation (psyche, subtle, causal, non-dual) leading to egotranscendence and ultimately the realization of non-dual being in which any vestiges of the separate or archetypal self are dissolved in total surrender to the vastness of existence. Attachment to manifest existence and physical embodiment is let go in the eternal moment of now, and there is a spontaneous embracement of play in the vast field of consciousness Rajneesh [2].

The problem is that the medical industry particularly doctors are stuck in the Western egoic fight against the void typical of the Western existential movement who typically tried to fill up or cover the void of nothingness in existence, the abyss Tzu [1]. In this mad frenzy to somehow defeat death, and sometimes regressing to a pure ego identity of being god-like in level five, formal identity, of Wilber's spectrum model, an all or nothing battle is taken up that does not consider a host of factors such as spiritual development, quality of life, acceptance of death, aesthetics, relationship-family issues and ultimately non-dual being. Even the will to meaning of logotherapy of level six is often forgotten. A recent clinical example will demonstrate the realities of this death phobia, a fear of dying orientation in medical practice. A well-known academic in his 60 's called me up for an emergency consultation around his prostate cancer. He was scheduled in six days for a radical proctectomy, which means actually taking the prostrate out completely. This is indeed a radical procedure, effective in eliminating cancer if it is limited to the prostrate, but with huge side effects over a long time including depletion of sex drive, inability to have an erection, no sperm releasement, and various problems around urinary drippage, and control often leading to long term diaper usage, and all the resulting psychological implications.

This academic was horrified but was being pressured by everybody especially his urologist to take the deal and accept the operation, "This way, at least you live," he was told. When he came to see me the next day, I told him "Halt, let's look at the facts. You have a medium growth form of cancer, not the trivial kind, but not the severe kind either, just the middle kind that needs to be paid attention to with treatment. But the survivor rate for prostate cancer is above $90 \%$, so you actually have lots of options along the chemotherapy-radiation path as well as a host of alternative healing remedies. I am not sure the radical proctectomy is a good path for you as it will feel more like a medical induced suicide as your sex life completely drops away, there is a loss of a sense of virility, and there may be a host of urinary problems. I wouldn't do it." Instant relief swept over this man's face, "Thank you, I needed to hear that, it feels like I have an ally. I am cancelling the operation. And if the doctor doesn't like it, I will find another doctor to work 
with or a different cancer clinic." He had his courage back. And that was basically it for the consultation, and off he went.

I spoke to him briefly almost two years later, and the cancer was in remission, things were clean he was told, but they were continuing to monitor him after his successful treatment including using alternative remedies as there was still a risk of the cancer coming back. My master, Bhagwant Shree Rajneesh, renamed Osho in the last year of his life, always said so much of life is about the art of dying. Here is a quote from his discourse series on Zen: The Path of Paradox: Death is not the enemy. It appears to be so because we cling too much to life. The fear of death arises out of the clinging. And because of this clinging we are unable to know what life is too...Death is like the night. Life is yang and death is yin. Life is male, death is female. Life is aggression, ambition - a great effort

ISSN: 2574-1241

DOI: 10.26717/BJSTR.2020.24.004043

Gary Tzu. Biomed J Sci \& Tech Res

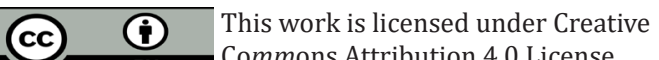

Submission Link: https://biomedres.us/submit-manuscript.php to conquer many things. And death is relaxation from all aggression - an inward journey. One relaxes into oneself. Zen people call it "the asylum of rest." Rajneesh [2]. It is clear the medical profession clings on to life too much and needs to befriend death so suitable medical treatments can be undertaken. It is here that the nursing profession seems to be far ahead of the physicians in embracing the transformational path of the art of dying and being able to empathically communicate that understanding to patients. It is my hope that the physician community, and medical science in general, will arise to the occasion in embracing the art of dying so the quality of medically appropriate treatment can greatly improve.

\section{References}

1. Tzu G (2014) Beyond addiction to awakening. Seattle WA: Create Space.

2. Rajneesh BS (1979) Zen: The path of paradox, Vol.3. Poona India: Rajneesh Foundation.

$\begin{array}{ll}\text { BIOMEDICAL } & \text { Assets of Publishing with us } \\ \text { RESEARCHES } & \text { - Global archiving of articles } \\ \text { - Immediate, unrestricted online access } & \text { - Rigorous Peer Review Process } \\ & \text { - Authors Retain Copyrights } \\ \end{array}$

